\title{
Superior mesenteric vein thrombosis after colectomy in a patient with Crohn's disease
}

\author{
Andrew S Ross, Arunas Gasparaitis, Roger Hurst, Stephen B Hanauer and David T Rubin
}

Nature Clinical Practice Gastroenterology \& Hepatology (2005) 2: 281-285 [doi:10.1038/ncpgasthep0195]

doi:10.1038/ncpgasthep0285

\section{ERRATUM}

In the June 2005 issue, Figures 2 and

3 in the Case Study by Ross et al. were incorrectly printed in black and white. The color figures are reproduced below with their original published legends.

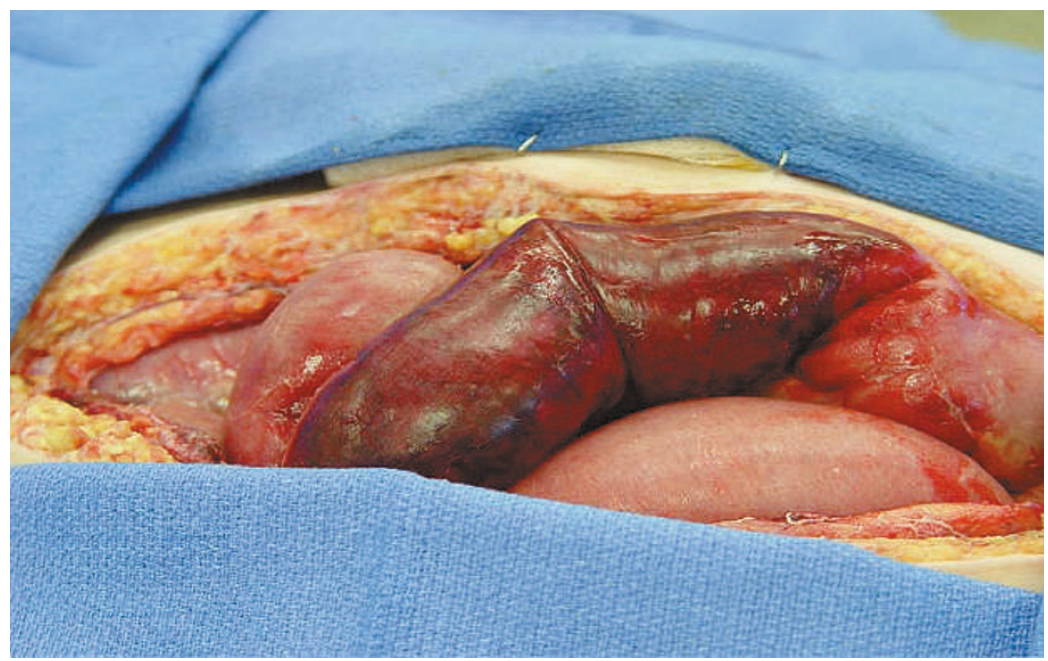

Figure 2 Findings at initial exploratory laparotomy showing extreme venous congestion of the small intestine.

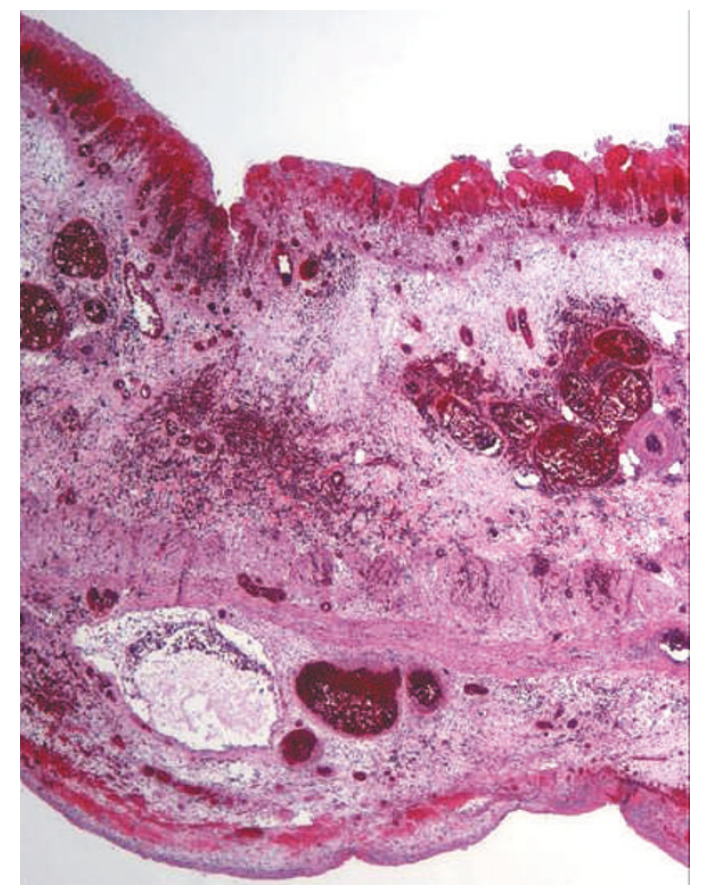

Figure 3 Representative histopathologic specimen from the resected small intestine revealing diffuse, severe mucosal necrosis. 